ORIGINAL ARTICLE

\title{
FAST on operational military deployment
}

\author{
A J Brooks, V Price, M Simms
}

Emerg Med J 2005;22:263-265. doi: 10.1136/emj.2004.014308

Background and objective: Handheld ultrasound, because of its light weight, size, rugged design, and relative simplicity of use is ideal for use on operational military deployment. These machines have been used in the diagnosis of a range of traumatic conditions including abdominal, thoracic, and extremity trauma in the hospital environment, yet few data exist on their use during military operations. This paper

See end of article for authors' affiliations

......................

Correspondence to:

A Brooks, Trauma Center at Penn, Hospital University of Pennsylvania, 3440 Market Street, PA

USA; adambrooks@ doctors.org.uk

Accepted for publication 22 March 2004 presents experience of handheld focused assessment with sonography for trauma (FAST) on operational military deployment.

Method: Over a two month period, handheld FAST was performed by a single surgeon during the circulation phase of the primary survey in trauma patients presenting to the British Military Hospital in Iraq. Results: Fifteen from casualties underwent a FAST examination. Ten were victims of blunt trauma, two had received injuries anti-personnel mines, and three had penetrating injuries from ballistic trauma. There was one positive FAST, confirmed at laparotomy as bleeding from a liver injury. Thirteen scans were negative and remained negative on repeat FAST at 6 hours. One further patient with a negative FAST underwent laparotomy because of transectory, there was no intra-abdominal blood or fluid at surgery.

Conclusion: Handheld FAST is a valuable technique for investigating abdominal or thoracic bleeding in single or multiple casualty events on operational military deployment.
$\mathrm{F}$ ocused assessment with sonography for trauma (FAST) in the emergency department has been well validated in studies of patients with abdominal injury ${ }^{12}$ and the technique has been extended for the detection of haemothorax. ${ }^{3}{ }^{4}$ Handheld ultrasound, because of its light weight, size, and relative simplicity of use, is proving to be an increasingly valuable tool in the diagnosis of a range of traumatic conditions including haemoperitoneum, ${ }^{5}$ haemothorax, ${ }^{6}$ pneumothorax, ${ }^{78}$ and extremity trauma. ${ }^{9}$ These attributes and the development of rugged machines that can withstand the rigours of the military make handheld ultrasound ideal for use on operational deployment. To date handheld systems have been successfully used in Kosovo, Afghanistan, and, most recently, in Iraq.

There are few data on the use of FAST on military deployment. We report our experience of non-radiologist FAST during operational deployment in Iraq.

\section{METHODS}

Over a two month period all trauma patients who presented to the British Military Hospital in Iraq with clinical signs suggestive of abdominal injury or an appropriate mechanism of injury underwent FAST. The scans were performed by a single surgeon with experience of handheld ultrasound in the evaluation of trauma, using the four views (pericardial, perihepatic, perisplenic, and pelvic) described by Rozycki et al ${ }^{2}$ with the addition of thoracic windows for the detection of haemothorax. The scans were undertaken using a Sonosite 180plus (Sonosile Bothell, WA) handheld system with a 35 MHz C60 transducer.

FAST was performed during the circulation phase of the primary survey as a standard part of resuscitation and evaluation of trauma patients. Where free intraperitoneal fluid was not demonstrated the scans were repeated six hours after resuscitation.

\section{RESULTS}

A total of 15 injured casualties were admitted to the resuscitation room during the two-month period. Ten were victims of blunt trauma following motor vehicle crashes, two had received injuries as a result of anti-personnel mines, and three had penetrating injuries from ballistic trauma including one with a pelvic/right iliac fossa high-energy transfer wound. On three occasions, three patients were admitted for resuscitation at once.

Of the initial FAST scans, 14 did not demonstrate free fluid. Thirteen of these patients had a repeat ultrasound scan after six hours. No free fluid was detected by these repeat scans. All 13 patients recovered to discharge or aeromedical evacuation at 72 hours and the introduction of food without the development of intra-abdominal sequelae. The fourteenth patient underwent a laparotomy to exclude intra-abdominal pathology because of the location of the high-energy transfer wound in the right iliac fossa. At surgery there was no intraabdominal blood or fluid, the bullet had destroyed the ileum bone displacing a fragment medially causing two tiny puncture wounds of the caecum-these were oversewn.

One FAST scan was positive-the diagnosis being made within 30 seconds of admission (fig 1). The patient had been involved in a motor vehicle crash and was admitted with normal vital signs and moderate abdominal tenderness initially. The patient was immediately taken to theatre for a laparotomy where a grade $\mathrm{V}$ liver injury with a retrohepatic caval injury was discovered. Following a damage control procedure and second laparotomy he succumbed to his injuries.

\section{DISCUSSION}

FAST is widely accepted for evaluating abdominal trauma, and several hospital based series of more than 1000 patients have been reported with sensitivity and specificity in the region of $90 \%{ }^{10}{ }^{11}$ Sufficient data also exist to support the use of FAST by non-radiologists. ${ }^{12}{ }^{13}$ Handheld ultrasound for FAST has also been successfully validated against both current investigations ${ }^{14}$ and alternative platform or trolley mounted machines ${ }^{15}$ and has been shown to provide images of sufficient quality to allow accurate diagnosis of intraabdominal free fluid. 


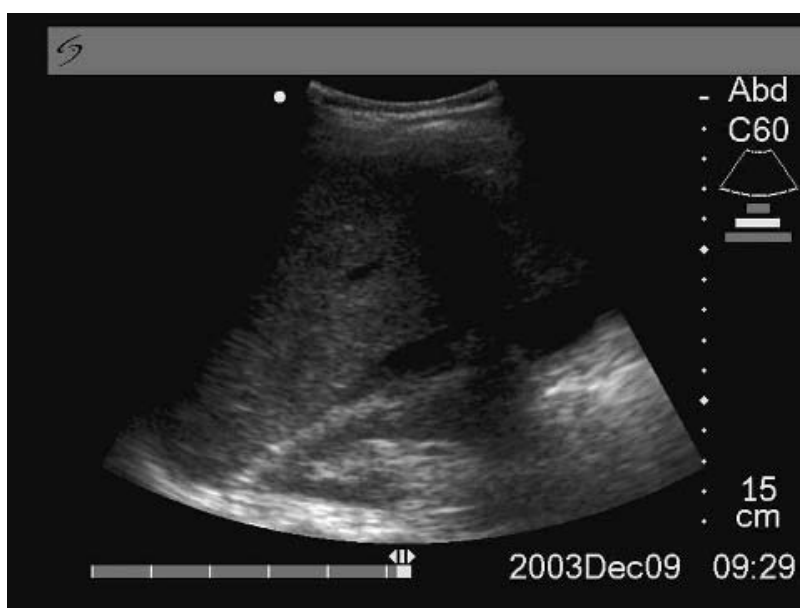

Figure 1 Positive perihepatic focused assessment with sonography for trauma (FAST). Blood is visible between the liver and right kidney.

In military hospitals, if FAST is not available, the assessment of the abdomen relies on clinical evaluation as computed tomography is seldom available. Although diagnostic peritoneal lavage may theoretically be available, the technique suffers, as in civilian practice, because of lack of equipment, insufficient experience, and limited laboratory support. ${ }^{16}$ If FAST had not been available in the hospital in Iraq, the patient with a positive scan in this series would probably have undergone an exploratory laparotomy after other sources of haemorrhage had been excluded.

Data on the use of handheld ultrasound in austere locations or from military deployment are limited. Dulchavsky's group have evaluated a range of ultrasound techniques including FAST for use on the International Space Station. ${ }^{17}$ They have recently submitted their experience of focused ultrasound on the International Space Station (Sargsyan AE et al, manuscript in preparation). In continuation of their interest in ultrasound in austere locations, they have also published a case report of the ultrasound diagnosis of extremity trauma on military deployment. ${ }^{18}$

Handheld ultrasound has become a routinely deployed asset within the Defence Medical Services and training courses exist to teach military surgeons the FAST technique. However, data on its use on military deployment are sparse. Our experience of FAST in 15 consecutive patients during operational deployment demonstrates that it is a valuable tool for the assessment of the trauma patient both at a forward deployed surgical facility and within a field hospital. In recognition of its true value as a "rule-in" rather than a "rule-out" investigation, we followed the guidelines suggested at the international consensus meeting ${ }^{19}$ and employed a six hour follow up scan in all appropriate patients. No intra-abdominal free fluid was detected on the repeat scans.

One of the advantages of handheld systems is their manoeuvrability especially during resuscitation, compared with larger, traditional platform or trolley mounted systems. This, coupled with battery power rather than relying on the relatively fragile mains supply, allows ease of access to the patient, which, within the limited space in a field hospital is extremely valuable.

We did not experience the technical problems associated with using handheld ultrasound in high levels of ambient light that have been mentioned in previous anecdotal reports. However, we did notice some degradation in the life of the battery that may have been associated with storage of the equipment in high temperatures during the summer months.

One of the potential drawbacks of FAST for military use is the poor sensitivity in penetrating trauma. ${ }^{20}{ }^{21}$ In fact, blunt trauma remains commoner that penetrating injury in military exercises except during war. ${ }^{22}$ In the evaluation of penetrating thoracoabdominal injury in the military, ultrasound is a rapid and valuable triage tool, that when positive directs the surgeon to the site of haemorrhage. However, in recognition of the poor sensitivity, a policy of mandatory laparotomy for penetrating abdominal wounds should still be followed.

Following the Armenian earthquake in 1988, Sarkisian et al demonstrated the value of ultrasound in the mass casualty scenario where it was used to assess more than 300 people. ${ }^{23}$ We used FAST as a rapid triage tool in three multiple casualty incidents. In each case ultrasound was able to provide a rapid assessment of the chest and abdomen as potential sources of haemorrhage and the results were available considerably before other investigations. Handheld ultrasound was extremely valuable in this situation and assisted in the surgical triage of multiple casualties.

\section{CONCLUSION}

Handheld FAST is a valuable technique on operational military deployment and can provide rapid and accurate diagnosis of abdominal or thoracic bleeding in single or multiple casualty events.

\section{ACKNOWLEDGEMENT}

The authors wish to acknowledge the Drummond Foundation's support of research into the military applications of handheld ultrasound.

\section{Authors' affiliations}

A J Brooks, Hospital University of Pennsylvania, Philadelphia, PA, 2nd Medical Brigade RAMC(V), USA

V Price, Frimley Park Hospital Frimley, UK

M Simms, Derriford Hospital, Plymouth, UK

Competing interests: none declared

\section{REFERENCES}

1 Rozycki GS, Oschner MG, Jaffin JH, et al. Prospective evaluation of surgeons' use of ultrasound in the evaluation of trauma patients. J Trauma 1993;34:516-26.

2 Rozycki GS, Ochsner GM, Schmidt JA. A prospective study of surgeonperformed ultrasound as the primary adjuvant modality for injured patient assessment. J Trauma 1995;39:492-500.

3 Ma OJ, Mateer JR, Ogata $M$, et al. Prospective analysis of a rapid trauma ultrasound examination performed by emergency physicians. J Trauma 1995; 38:879-85.

4 Sisley AC, Rozycki GS, Ballard RB, et al. Rapid detection of traumatic effusion using surgeon-performed ultrasound. J Trauma 1998;44:291-7.

5 Brooks AJ, Davies B, Connolly J. Prospective evaluation of handheld ultrasound in the diagnosis of blunt abdominal trauma. J Roy Army Med Corps 2002;148:19-22.

6 Brooks A, Davies B, Smethhurst M, et al. Emergency ultrasound in the acute assessment of haemothorax. Emerg Med J 2004;21:44-6.

7 Dulchavsky SA, Hamilton DR, Diebel LN, et al. Thoracic ultrasound diagnosis of pneumothorax. J Trauma 1999;47:970-1.

8 Dulchavsky SA, Kirkpatrick AW, Billica RD, et al. Prospective evaluation of thoracic ultrasound in the detection of pneumothorax. J Trauma 2001;50:201-5.

9 Dulchavsky SA, Henry SE, Moed BR, et al. Advanced ultrasonic diagnosis of extremity trauma: the faster examination. J Trauma 2002;53:28-32.

10 McKenney MG, Martin L, Lentz K, et al. 1000 consecutive ultrasounds for blunt abdominal trauma. J Trauma 1996;40:607-12.

11 Dolich MO, McKenney MG, Varela JE, et al. 2576 ultrasounds for blunt abdominal trauma. J Trauma 2001;50:108-12.

12 Rozycki GS, SS. Trauma Ultrasound for Surgeons, In: Staren E, Shackford S, eds. Ultrasound for the Surgeon. New York: Lippincott-Raven, 1997:120-35.

13 Buzzas GR, Kern SJ, Smith RS, et al. A comparison of sonographic examinations for trauma performed by surgeons and radiologists. J Trauma 1998;44:604-6, discussion 607-8. 
14 Brooks A, Davies B, Smethhurst $M$, et al. Prospective evaluation of nonradiologist performed emergency abdominal ultrasound for haemoperitoneum. Emerg Med J (in press).

15 Kirkpatrick AW, Simons RK, Brown R, et al. The hand-held FAST: experience with hand-held trauma sonography in a level-I urban trauma center. Injury 2002;33:303-8.

16 Maxwell-Armstrong C, Brooks AJ, Field $M$, et al. Diagnostic peritoneal lavage. Should trauma guidelines be revised? Emerg Med J 2002;19:524-5

17 Kirkpatrick AW, Hamilton DR, Nicolaou S, et al. Focused assessment with sonography for trauma in weightlessness: a feasibility study. J Am Coll Surg 2003; 196:833-44.

18 Kirkpatrick AW, Brown R, Diebel LN, et al. Rapid diagnosis of an ulnar fracture with portable hand-held ultrasound. Mil Med 2003;168:312-13.
19 Scalea TM, Rodriguez A, Chiu WC, et al. Focused assessment with sonography for trauma (FAST): results from an international consensus conference. J Trauma 1999;46:444-72.

20 Udobi KF, Rodriguez A, Chiu WC, et al. Role of ultrasonography in penetrating abdominal trauma: a prospective clinical study. J Trauma 2001;50:475-9.

21 Boulanger BR, Kearney PA, Tsuei B, et al. The routine use of sonography in penetrating torso injury is beneficial. J Trauma 2001;51:320-5.

22 Roberts P. Patterns of injury in military operations. Curr Anaesth Crit Care 2003;13:243-8.

23 Sarkisian AE, Khondkarian RA, Amirbekian NM, et al. Sonographic screening of mass casualties for abdominal and renal injuries following the 1988 Armenian earthquake. J Trauma 1991;31:247. 